\title{
Statistical Regions of the United Kingdom
}

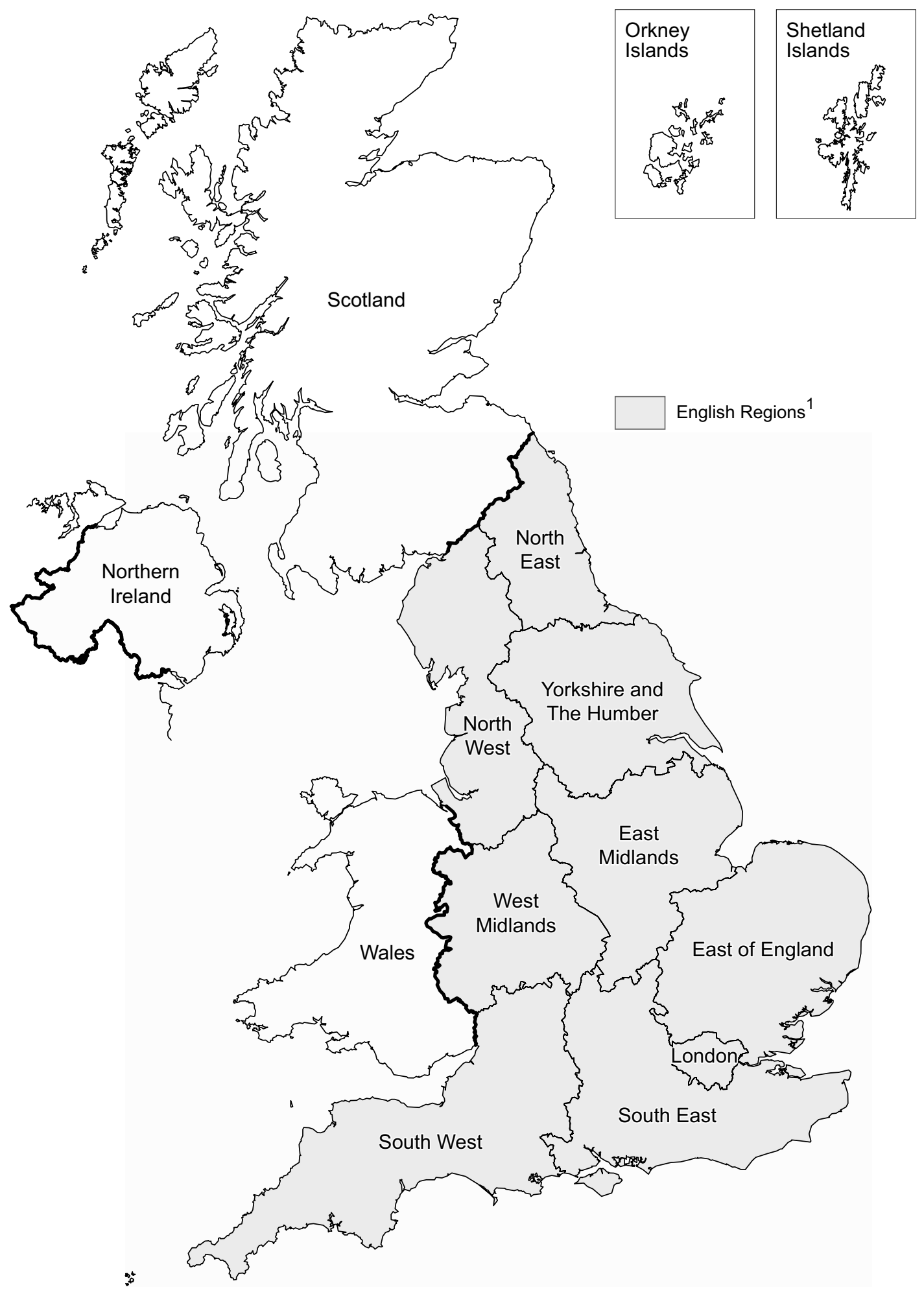

Contains Ordnance Survey data @ Crown copyright and database right 2011

1 Government Offices for the Regions (GORs) closed at the end of March 2011 and are now referred to as 'regions' for statistical purposes. 